\section{Detection of Extended- Spectrum Beta-Lactamase producing Escherichia coli from mesenteric lymph nodes of wild boars (Sus scrofa)}

\author{
Silvia Bonardi, ${ }^{1}$ Clotilde Silvia Cabassi, ${ }^{1}$ \\ Simona Longhi, ${ }^{1}$ Federico Pia, ${ }^{1}$ \\ Margherita Corradi, ${ }^{2}$ Stefano Gilioli, ${ }^{2}$ \\ Erika Scaltriti ${ }^{3}$ \\ ${ }^{1}$ Department of Veterinary Sciences, \\ University of Parma; ${ }^{2}$ Management \\ Body for Parks and Biodiversity "Emilia \\ Occidentale", Sala Baganza (PR); \\ ${ }^{3}$ Experimental Institute for \\ Zooprophylaxis of Lombardy and \\ Emilia-Romagna Regions, Risk Analysis \\ and Genomic Epidemiology Unit, \\ Parma, Italy
}

\begin{abstract}
Wild boars (Sus scrofa) are increasing in several European countries, including Italy. In areas with intensive animal farming, like the Italian Emilia-Romagna region, they are likely to be exposed to antimicrobialresistant (AMR) bacteria of livestock origin. In 2017-2018, 108 mesenteric lymph nodes samples were collected from 108 wild boars hunted in Parma province, Emilia-Romagna region, to be tested for ESBL- and carbapenemase-producing Escherichia coli. One isolate (WB-21L) out of $108(0.9 \%)$ was phenotypically confirmed as ESBLproducing $E$. coli. The strain WB-21L was tested by PCR for the genes $b l a_{\mathrm{SHV}}, b l a_{\text {СТХ-M, }}$ bla $a_{\mathrm{TEM}}, b l a_{\mathrm{AmPC}}, b l a_{\mathrm{KPC}}, b l a_{\mathrm{NDM}}$, bla $_{\mathrm{VIM}}$, bla $\mathrm{IMP}$, $b l a_{\mathrm{OXA}-48,}, b l a_{\mathrm{SPM}}, b l a_{\mathrm{BIC}}, b l a_{\mathrm{SIM}}, b l a_{\mathrm{DIM}}, b l a_{\mathrm{GIM}}$, $b l a_{\text {AIM }}$, resulting positive for TEM $\beta$ lactamase. Resistance to ampicillin, amoxicillin/clavulanic acid, streptomycin, sulfasomidine, tetracycline and trimethoprim confirmed the multi-resistance nature of the strain WB-21L. Nine E.coli isolates showed resistance to meropenem by the Kirby Bauer test but none of them showed Meropenem MIC values indicative of resistance. In conclusion, the present study shows the presence of ESBL E. coli in wild boars and the possible risk of transfer to game meat handlers and consumers. Future studies are needed to better evaluate the sources of AMR bacteria in wildlife.
\end{abstract}

\section{Introduction}

Transmission of antimicrobial-resistant (AMR) bacteria or their resistance determinants from food-producing animals to humans has been a public health concern for decades (Moyaert et al., 2014). Recently, the role of wild animals in transmitting AMR microorganisms to humans has been investigated in many countries. In particular, wild boar (Sus scrofa) populations are increasing in several European countries, including Italy, where they represent the most common among wild ungulates (Carnevali et al., 2009). Wild boars are omnivorous and travel large distances for searching food, thus ingesting a large variety of food, including waste (Literak et al., 2009). As they often inhabit near humans and livestock animal populations, they can be contaminated by AMR bacteria of human or livestock origin.

Among AMR bacteria, $\beta$-lactamaseproducing microorganisms are of concern both for human and animal health (Li et al., 2007; Poeta et al., 2009). $\beta$-lactam resistance develops because of different mechanisms, such as inaccessibility of the drugs to their target, target alterations and/or inactivation of the drugs by specific enzymes called $\beta$-lactamases. The genes encoding $\beta$ lactamases often coexist with other antimicrobial resistance determinants and can be associated with transposons/integrons, thus increasing the potential dissemination of the resistance genes among bacterial species and the emergence of multidrug resistant (MDR) microorganisms (Li et al., 2007).

One of the most urgent areas of drug resistance is the evolution of extendedspectrum $\beta$-lactamase (ESBL) and carbapenem resistance in Enterobacteriaceae which has spread globally in the last decade (WHO, 2014). Antimicrobial-therapy with cephalosporins (i.e. cefotaxime, ceftazidime, ceftriaxone and cefepime) is considered one of the most important treatment options for serious infections due to extraintestinal Escherichia coli in humans (Pitout, 2012). The development of resistance against carbapenems (ertapenem, imipenem, meropenem, doripenem) among Enterobacteriaceae is of special concern, because they are often the last line of defence against multi-drug resistant invasive microorganisms belonging to this family (Pitout, 2012).

Among E. coli, the production of $\beta$-lactamases remains the most important mediator to $\beta$-lactam resistance. Classification of $\beta$-lactamases is complex and it is based either on molecular classification (Ambler classification) or on functional classification (Bush Jacoby classification) (Ambler, 1980; Bush and Jacoby, 2010). The Ambler classification is based on amino-acid sequences of the enzymes and divides $\beta$ lactamases into four classes, namely A, C and $\mathrm{D}$ which require serine for $\beta$-lactam
Correspondence: Silvia Bonardi, Department of Veterinary Sciences, University of Parma, Strada del Taglio, 10, 43126, Parma, Italy.

Tel.: +39.0521.032744

E-mail: silvia.bonardi@unipr.it

Key words: Escherichia coli, Wild boars, ESBL, Antimicrobial resistance.

Contributions: the authors contributed equally.

Conflict of interests: the authors declare no potential conflict of interests.

Funding: The study was funded by the University of Parma.

Received for publication: 19 July 2018.

Revision received: 15 November 2018.

Accepted for publication: 15 November 2018.

This work is licensed under a Creative Commons Attribution-NonCommercial 4.0 International License (CC BY-NC 4.0).

CCopyright S. Bonardi et al., 2018

Licensee PAGEPress, Italy

Italian Journal of Food Safety 2018; 7:7707 doi:10.4081/ijfs.2018.7707

hydrolysis, and class B metallo-enzymes which require divalent zinc ions for $\beta$-lactam hydrolysis. The Bush Jacoby classification uses substrate or inhibitor profiles to divide $\beta$-lactamases into three groups: 1) cephalosporinases; 2 ) serine- $\beta$-lactamases; 3) metallo- $\beta$-lactamases.

A commonly used definition is that the ESBLs are $\beta$-lactamases capable of conferring bacterial resistance to penicillin, first-, second-, third-, and fourth-generation cephalosporins, and aztreonam, but neither to cephamycins or carbapenems, by hydrolysis of these antibiotics, and which are inhibited by $\beta$-lactamase inhibitors such as clavulanic acid, sulbactam and tazobactam and by diazabicyclooctanones (Paterson and Bonomo, 2005; Nordman et al., 2012). ESBL-producing $E$. coli have increased constantly during the 2000 s, with several reports of nosocomial and community isolates resistant to these antimicrobial classes (Pitout, 2012). The ESBL pandemic in $E$. coli is mostly linked to CTX-M $\beta$-lactamases, and especially CTX-M-15 (Pitout, 2012) but other enzymes may be responsible for $\beta$-lactams inactivation. For example, during the 1980s and 1990s, the majority of the ESBLs were the SHV or TEM types (Paterson and Bonomo, 2005).

Human invasive E. coli isolates resistant to carbapenems have been identified in several EU countries. However, prevalence of resistant isolates was low, ranging from $0.0 \%$ to $1 \%$ in 2016 , and not comparable to 
resistance among other bacterial species as Klebsiella pneumoniae, Pseudomonas aeruginosa and Acinetobacter baumannii. In Italy, prevalence of carbapenem-resistant human invasive $E$. coli was $0.3 \%$ in 2016 (ECDC, 2017). Among livestock animals, pigs were found to be positive for a class $B$ metallo- $\beta$-lactamase-producing $E$. coli harbouring the $b l a_{\mathrm{VIM}-1}$ gene in Germany (Falgenhauer et al., 2017) and a class D oxacillinases-producing $E$. coli carrying the $b l a_{\text {OXA-181 }}$ gene in Italy (Pulss et al., 2017).

Main purpose of study was the detection of ESBL-producing and carbapenemase-producing E. coli in wild boars hunted in northern Italy, Emilia-Romagna region, to assess the likely role of wild animals living in proximity of livestock farms to act as vectors of AMR bacteria. To our knowledge, this is the first Italian study on ESBLand carbapenemase-producing $E$. coli in wild boars, which aimed at the evaluation of the wildlife/livestock interface in the maintenance of AMR bacteria in an area characterized by intensive livestock farming.

\section{Materials and Methods}

\section{Detection of $E$. coli from mesenteric lymph nodes}

A total of 108 MLN samples were aseptically collected from the small intestines of 108 wild boars hunted in Parma province, Emilia Romagna Region, northern Italy in 2017-2018. Mesenteric lymph nodes were preferred to faecal samples, because it is still not clear if $E$. coli in faeces are just shedded in short terms, present transient, or cause long term colonization of the gut asymptomatically (Guenther et al., 2011). For this survey only animals dead since less than 5 hours were selected. MLN were washed with sterile saline solution and decontaminated using ethilyc alcohol before being placed in sterile containers. The samples were transported to the laboratory at refrigeration conditions. Before being tested, they were cut in small pieces $(0.2-0.3 \mathrm{~cm})$ by using sterile scissors. Sample size varied among animals, ranging from 2.5 to $25 \mathrm{~g}$ (average tested weight: $21.5 \mathrm{~g}$ ). One to ten dilutions were realized in Buffered Peptone Water (BPW; Oxoid, Basingstoke, UK) and incubated at $37^{\circ} \mathrm{C}$ for 18-20 h. A $10 \mu \mathrm{L}$ loopful of the cultures was streaked onto Tryptone Bile X-Glucuronide (TBX; Biolife Italiana, Milan, Italy) agar plates, incubated aerobically at $44 \pm 1^{\circ} \mathrm{C}$ for $21 \pm 3 \mathrm{~h}$. At least three blue-green colonies per sample were selected and plated onto Tryptone Soya Agar (TSA, Oxoid) and Tryptone Soya Broth (TSB, Oxoid), which were incubated at $44 \pm 1^{\circ} \mathrm{C}$ for $21 \pm 3 \mathrm{~h}$. Indole production was tested by adding James' reagent to TSB cultures. From TSA plates of indole-positive cultures, one well isolated colony was subjected to species identification with the microsubstrate system Microgen ${ }^{\circledR}$ GN-A (Biogenetics, Padua, Italy).

\section{Testing for ESBL and carbapene- mase production}

From Escherichia coli isolates, a culture of 0.5 Mac Farland's was prepared and seeded onto a Mueller Hinton agar (MHA; Oxoid) plate. The ESBL test was performed by the Kirby-Bauer test following CLSI recommendations (2018a). In addition, carbapenem resistance was evaluated. Disks containing cefotaxime (CTX; $30 \mu \mathrm{g})$, ceftazidime (CAZ; $30 \mu \mathrm{g}$ ) and meropenem (MEM; $10 \mu \mathrm{g}$ ) were used and MHA plates were incubated at $35 \pm 2{ }^{\circ} \mathrm{C}$ for $16-18 \mathrm{~h}$. Inhibition diameter zones $\leq 22 \mathrm{~mm}$ for CTX and $\leq 17 \mathrm{~mm}$ for CAZ were considered indicative of ESBL production (CLSI, 2018a). For carbapenems, diameter zones $\leq 19 \mathrm{~mm}$ were considered indicative of nonsensitivity to meropenem. Escherichia coli ATCC 25922 was used as quality control microorganism. All the strains which showed a diameter of less than $22 \mathrm{~mm}$ for cefotaxime and less than $17 \mathrm{~mm}$ for ceftazidime were selected for checking the ESBL production. Phenotypic identification of ESBL-producing isolates was performed by using the ESBL-Confirm Kit (Rosco Diagnostica, Taastrup, Denmark) following the manufacturer's instructions. Briefly, disks containing cefotaxime $(30 \mu \mathrm{g})$, cefotaxime and clavulanic acid $(30 \mu \mathrm{g} ; 10 \mu \mathrm{g})$, ceftazidime $(30 \mu \mathrm{g})$ and ceftazidime/clavulanic acid $(30 \mu \mathrm{g} ; 10 \mu \mathrm{g})$ were aseptically placed on MHA plates. After incubation at $35 \pm 2{ }^{\circ} \mathrm{C}$ for $18-24 \mathrm{~h}$, ESBL-producing organisms were detected by an at least 5 $\mathrm{mm}$ increasing of zone around cefotaxime/clavulanate and/or at least $5 \mathrm{~mm}$ around ceftazidime/clavulanate. For carbapenem resistance, isolates showing a diameter zone equal or less than $19 \mathrm{~mm}$ for meropenem were tested by the Minimum Inhibitory Concentration (MIC) test following the CLSI guidelines (2018b). Isolates suspicious for carbapenemase-production show Meropenem MIC value $\geq 4.0 \mu \mathrm{g} / \mathrm{mL}$.

\section{Testing for $\boldsymbol{\beta}$-lactamases genes}

To confirm $\beta$-lactamase production, the isolates identified by phenotypic tests as ESBL or carbapenemase producers should be tested by PCR for the following genes: bla $a_{\mathrm{SHV}}, b l a_{\mathrm{CTX}-\mathrm{M},}, b l a_{\mathrm{TEM}}, \quad b l a_{\mathrm{AmpC}}, b l a_{\mathrm{KPC}}$, bla $\mathrm{NDM}$, bla $_{\mathrm{VIM}}$, bla $_{\mathrm{IMP}}$, bla $a_{\mathrm{OXA}-48,}$, $l a_{\mathrm{SPM}}$, bla $a_{\mathrm{BIC}}$, $b l a_{\mathrm{SIM}}, b l a_{\mathrm{DIM}}, b l a_{\mathrm{GIM}}, b l a_{\mathrm{AIM}}$. PCR were performed as single reactions to avoid non-specific amplification according to protocols reported in Table 1. Presence or absence of these genes were evaluated without defining the allelic variants.

\section{Testing for antimicrobial- resistance of ESBL $E$. coli}

Antimicrobial susceptibility was tested using the Kirby Bauer disc-diffusion method, according to the recommendations of the CLSI (2018a). Mueller-Hinton Agar (Oxoid) and commercial antimicrobial

Table 1. List of PCR detected genes with their amplicon sizes and references to protocols.

$\begin{array}{llll}\text { Genes } & \text { Function } & \text { Amplicon Sive (bp) } & \text { Bibliography } \\ \text { blaSHV } & \text { Cephalosporinase } & 747 & \text { Monstein et al., 2007 } \\ \text { blaCTX-M } & & 593 & \\ \text { blaTEM } & 445 & \text { Pérez-Pérez and Hanson, 2002 } \\ \text { blaAmpC - MOX-M } & 520 & \\ \text { blaAmpC - CIT-M } & 462 & \\ \text { blaAmpC - DHA-M } & 405 & \\ \text { blaAmpC - ACC-M } & & 346 & \\ \text { blaAmpC - EBC-M } & & \text { Poirel et al., 2011 } \\ \text { blaAmpC -FOX-M } & & 190 & \\ \text { blaKPC } & \text { Carbapenemase } & 798 & \\ \text { blaNDM } & & 621 & \\ \text { blaVIM } & 390 & \\ \text { blaIMP } & 232 & \\ \text { blaOXA-48 } & & \\ \text { blaSPM } & 2738 & \\ \text { blaBIC } & 537 & \\ \text { blaSIM } & 570 & \\ \text { blaDIM } & 699 & \\ \text { blaGIM } & 477 & \\ \text { blaAIM } & 322 & \end{array}$


susceptibility discs (HI-Media, Mumbai, India) were used. ESBL-producing $E$. coli were tested against 12 antimicrobials, i.e. amikacin $(30 \mu \mathrm{g})$, ampicillin $(10 \mu \mathrm{g})$, amoxicillin/clavulanic acid $(20 \mu \mathrm{g} / 10 \mu \mathrm{g})$, ciprofloxacin $(5 \mu \mathrm{g})$, chloramphenicol (30 $\mu \mathrm{g})$, gentamicin $(10 \mu \mathrm{g})$, kanamycin $(30 \mu \mathrm{g})$, nalidixic acid $(30 \mu \mathrm{g})$, streptomycin $(10 \mu \mathrm{g})$, sulphasomidine $(300 \mu \mathrm{g})$, tetracycline $(30$ $\mu \mathrm{g})$ and trimethoprim $(5 \mu \mathrm{g})$. MHA plates were incubated aerobically at $35 \pm 2^{\circ} \mathrm{C}$ for 18 $24 \mathrm{~h}$. Susceptibility results were categorized as susceptible or resistant according to the CLSI (2018a) recommendations.

\section{Results}

One E. coli isolate (WB-21L) out of 108 $(0.9 \%)$ was found to be resistant to cefotaxime and ceftazidime by the Kirby Bauer disc diffusion method. ESBL production was confirmed by the synergy test with clavulanic acid. By PCR, the isolate was positive for the $b l a_{\mathrm{TEM}}$ gene and negative for the other genes tested. The isolate showed resistant against ampicillin, amoxicillin/clavulanic acid, streptomycin, sulfasomidine, tetracycline and trimethoprim, thus confirm the multiresistance nature of the WB-21L isolate (R-type:AmcAmpCazCtxSSoTeTmp).

Nine E. coli isolates resistant to meropenem were detected by the disc diffusion method, but none of them showed Meropenem MIC values indicative of resistance.

\section{Discussion}

To our knowledge, this is the first identification of ESBL-producing $E$. coli in wild boars in Italy. The occurrence of ESBL $E$. coli in wild animals not exposed to antimicrobial agents is of concern, suggesting that the interface livestock/wildlife animals can be effective in maintaining AMR bacteria in the environment. Transmission to wild animals of ESBL bacteria is probably the last step of AMR bacteria environmental pollution.

ESBL isolates harbour resistant genes that code for a variety of $\beta$-lactamases. Since $\beta$-lactams are among the critically important antibiotics in veterinary medicine, acquired resistance to this large class of antimicrobials is not surprising. The genes encoding these enzymes often coexist with other antimicrobial resistance determinants and can also be associated with transposons/integrons, thus increasing the number of multidrug resistant bacteria as well as dissemination of the resistance determi- nants among bacterial species (Li et al., 2007). For these reasons, ESBL-producing $E$. coli strains may present a phenotype of multi-resistance that included antimicrobial agents of different families (Costa et al., 2009). In particular, plasmid-mediated cephalosporinase genes are often associated with coresistance to aminoglycosides, tetracycline and sulphonamides, as the consequence of the colocalization of resistance determinants on the same plasmid (Martinez-Martinez, 2008). This is in accordance with the R-type of the strain WB$21 \mathrm{~L}$, which showed resistance to third generation cephalosporins, streptomycin, tetracycline and sulphasomidine.

TEM is considered the archetypical plasmid-encoded $\beta$-lactamase (Davies and Davies, 2010). TEM-type beta-lactamases are derivatives of TEM-1, which was first detected in 1965 in an E. coli isolate from a patient in Greece, named Temoneira, and of TEM-2 and consist of more than 150 different enzymes (Guenther et al., 2011). bla TEM$^{-}$ type enzymes capable of degrading $\beta$-lactams have since then disseminated worldwide. Even if the allelic variant of the bla $_{\text {TEM }}$ enzyme harboured by the strain WB21L has not been yet identified, some variants have been previously found in ESBL $E$. coli from wild boars. This is the case of $E$. coli harbouring $b l a_{\text {TEM-1, }}$ which were identified in faecal samples of wild boars in Portugal (Poeta et al., 2009), Check Republic and Slovakia (Literak et al., 2009) and $E$. coli carrying $b l a_{\text {TEM-52b }}$ which were isolated from faeces of wild boars in the Check Republic and Slovakia (Literak et al., 2009). In Italy, ESBL E. coli harbouring $b l a_{\text {TEM-1, }}, \quad b l a_{\text {TEM-24, blaTEM-52 }}$ and $b l a_{\text {TEM-201 }}$ genes were detected in faeces of pigs and cattle (Stefani et al., 2014).

Concerning carbapenemase-producing E. coli, the results based on the Kirby Bauer disc diffusion test were not confirmed by Meropenem MIC test.

\section{Conclusions}

The global spread, rising incidence, and increased mortality of expanded-spectrum beta-lactamase (ESBL) E. coli infections over the past decades have made it one of the biggest threats to human health worldwide (Pitout, 2010). Several studies have demonstrated the occurrence of ESBL $E$. coli in farmed animals, as pigs, cattle and poultry, especially when the animals were treated with third- and fourth-generation cephalosporins (Hammerum et al., 2014; Dahms et al., 2015). The transfer of ESBLproducing $E$. coli to wild boars could be primarily caused by their habit to visit refuse sites and the proximity of animal farms, eat- ing waste containing resistant E. coli (Literak et al., 2009). Another source of ESBL $E$. coli in wildlife could be represented by the natural environment, contaminated by AMR bacteria dispersed by different routes, such as livestock manure, manure amended soil, and surface waters polluted with faeces (Kummerer, 2009).

Concerning food-safety, future studies should address whether ESBL E. coli can be transmitted by wild boars to the consumers and game meat handlers. The studies of antimicrobial drug resistance in animals living in different natural habitats are warranted to fully understand the importance of wildlife as a source of antimicrobial resistance for humans.

\section{References}

Ambler RP, 1980. The structure of beta-lactamases. Philos Trans R Soc Lond B 289:321-31.

Bush K, Jacoby JA, 2010. Updated functional classification of beta-lactamases. Antimicrob Agents Chemother 54:96976.

Carnevali L, Pedrotti L, Riga F, Toso S, 2009. Ungulates in Italy: Status, distribution, abundance, management and hunting of Ungulate populations in Italy. Biol Cons Fauna 117:1-168.

Clinical and Laboratory Standards Institute, 2018a. Performance Standards for Antimicrobial Susceptibility Testing, $28^{\text {th }}$ ed. CLSI supplement M100. Wayne, PA.

Clinical and Laboratory Standards Institute, 2018b. Methods for dilution antimicrobial susceptibility test for bacteria that grow aerobically; approved standard 11th Ed. CLSI: Wayne, Pennsylvania, USA, January 2018

Costa D, Vinué L, Poeta P, Coelho AC, Matos M, Sáenz Y, Somalo S, Zarazaga M, Rodrigues J, Torres C, 2009. Prevalence of extended-spectrum beta-lactamase-producing Escherichia coli isolates in faecal samples of broilers. Vet Microbiol 138:339-44.

Dahms C, Hübner NO, Kossow A, Mellmann A, Dittmann K, Kramer A, 2015. Occurrence of ESBL-producing Escherichia coli in livestock and farm workers in Mecklenburg-Western Pomerania, Germany. PLoS One 10:113.

Davies J, Davies D, 2010. Origin and evolution of antibiotic resistance. Microbiol Mol Biol Rev 74: 417-33.

European Centre for Disease Prevention and Control (ECDC), 2017. Surveillance of antimicrobial resistance in Europe 2016. Annual Report of the 
European Antimicrobial Resistance Surveillance Network (EARS-Net). Stockholm: ECDC.

Falgenhauer L, Ghosh H, Guerra B, Yao Y, Fritzenwanker M, Fischer J, Helmuth R, Imirzalioglu C, Chakrabor T, 2017. Comparative genome analysis of IncHI2 VIM-1 carbapenemase-encoding plasmids of Escherichia coli and Salmonella enterica isolated from a livestock farm in Germany. Vet Microbiol 200:114-7.

Guenther S, Ewers C, Wieler LH, 2011. Extended-spectrum beta-lactamases producing E. coli in wildlife, yet another form of environmental pollution? Front Microbiol 2:1-13.

Hammerum AM, Larsen J, Andersen VD, Lester CH, Skovgaard Skytte TS, Hansen F, Olsen SS, Mordhorst H, Skov RL, Aarestrup FM, Agersø Y, 2014. Characterization of extended-spectrum $\beta$-lactamase (ESBL)producing Escherichia coli obtained from Danish pigs, pig farmers and their families from farms with high or no consumption of third- or fourth-generation cephalosporins. J Antimicrob Chemoth 69:2650-7.

Kummerer K, 2009. Antibiotics in the aquatic environment - a review - part I. Chemosphere 75:417-34.

Li XZ, Mehrotra M, Ghimire S, Adewoye $\mathrm{L}, 2007$. $\beta$-Lactam resistance and $\beta$-lactamases in bacteria of animal origin. Vet Microbiol 121:197-214.

Literak I, Dolejska M, Radimersky T, Klimes J, Friedman M, Aarestrup
FM, Hasman H, Cizek A, 2009. Antimicrobial-resistant Escherichia coli in wild mammals in central Europe: multiresistant Escherichia coli producing extended-spectrum beta-lactamases in wild boars. J Appl Microbiol 108:1702-11.

Martinez-Martinez L, 2008. Extended-spectrum $\beta$-lactamases and the permeability barrier. Clin Microbiol Infect 14:82-9.

Monstein HJ, Ostholm-Balkhed A, Nilsson MV, Dornbush K, Nilsson LE, 2007. Multiplex PCR amplification assay for the detection of bla $_{\mathrm{SHV}}, \mathrm{bla}_{\mathrm{CTX}-\mathrm{M}}, \mathrm{bla}_{\mathrm{TEM}}$ genes in Enterobacteriaceae. Acta Pathol Microbiol Immunol Scand 115:1400-8.

Moyaert H, de Jong A, Simjee S, Thomas V, 2014. Antimicrobial resistance monitoring projects for zoonotic and indicator bacteria of animal origin: common aspects and differences between EASSA and EFSA. Vet Microbiol 171:279-83

Nordmann P, Dortet L, Poirel L, 2012. Carbapenem resistance in Enterobacteriaceae: here is the storm! Trends Mol Med 18:263-72.

Paterson DL, Bonomo RA, 2005. Extendedspectrum $\beta$-lactamases: an update. Clin Microbiol Rev 18:657-86.

Pérez-Pérez FJ, Hanson ND, 2002. Detection of Plasmid-Mediated AmpC b-Lactamase Genes in Clinical Isolates by using Multiplex PCR. J Clin Microbiol 40:2153-62.

Pitout JD, 2010. Infections with extendedspectrum beta-lactamase-producing enterobacteriaceae: changing epidemiology and drug treatment choices. Drugs 70:313-33.

Pitout, JD, 2012. Extraintestinal pathogenic Escherichia coli: an update on antimicrobial resistance, laboratory diagnosis and treatment. Expert Rev Anti Infect 10:1165-76.

Poeta P, Radhouani H, Pinto L, Martinho A, Rego V, Rodrigues R, Gonçalves A, Rodrigues J, Estepa V, Torres C, Igrejas G, 2009. Wild boars as reservoirs of extended-spectrum beta-lactamase (ESBL) producing Escherichia coli of different phylogenetic groups. J Basic Microbiol 49:584-8.

Poirel L, Walsh TR, Cuvillier V, Nordmann P, 2011. Multiplex PCR for detection of acquired carbapenemase genes. Diagn Microbiol Infect Dis 70:119-23.

Pulss S, Semmler T, Prenger-Berninghoff E, Bauerfeind R, Ewers C, 2017. First report of an Escherichia coli strain from swine carrying and OXA-181 carbapenemase and the colistin determinant MCR-1. Int J Antimicro Ag 50:232-6.

Stefani S, Giovanelli I, Anacarso I, Condò C, Messi P, de Niederhäusern S, Bondi M, Iseppi R, Sabia C, 2014. Prevalence and characterization of extended-spectrum beta-lactamase Enterobacteriaceae in food-producing animals in Italy. New Microbiol 37:551-5.

World Health Organization (WHO), 2014. Antimicrobial resistance: Global report on surveillance 2014. http://www.who. int/drugresistance/documents/surveillancereport/en/ 